Article

\title{
Emic Views of Community Resilience and Coastal Tourism Development
}

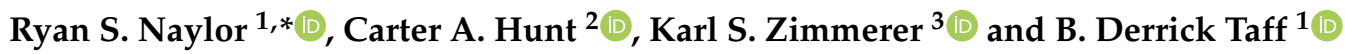 \\ 1 Department of Recreation, Park and Tourism Management, Pennsylvania State University, University Park, \\ State College, PA 16802, USA; bdt3@psu.edu \\ 2 Department of Recreation, Park and Tourism Management, and Anthropology, Pennsylvania State University, \\ University Park, State College, PA 16802, USA; cah59@psu.edu \\ 3 Department of Geography, Pennsylvania State University, University Park, State College, PA 16802, USA; \\ ksz2@psu.edu \\ * Correspondence: rsn16@psu.edu
}

Citation: Naylor, R.S.; Hunt, C.A.;

Zimmerer, K.S.; Taff, B.D. Emic Views of Community Resilience and Coastal Tourism Development. Societies 2021, 11, 94. https://doi.org/10.3390/ soc11030094

Academic Editors: Gregor Wolbring and Marko Perić

Received: 19 June 2021

Accepted: 4 August 2021

Published: 10 August 2021

Publisher's Note: MDPI stays neutral with regard to jurisdictional claims in published maps and institutional affiliations.

Copyright: (C) 2021 by the authors Licensee MDPI, Basel, Switzerland. This article is an open access article distributed under the terms and conditions of the Creative Commons Attribution (CC BY) license (https:/ / creativecommons.org/licenses/by/ $4.0 /)$.

\begin{abstract}
Coastal communities are among the most rapidly changing, institutionally complex, and culturally diverse in the world, and they are among the most vulnerable to anthropogenic change. While being a driver of anthropogenic change, tourism can also provide socio-economic alternatives to declining natural resource-based livelihoods for coastal residents. The purpose of this study is to assess the impact of small-scale cruise tourism on coastal community resiliency in Petersburg, Alaska. Exploring these impacts through resiliency theory's lens of exposure, sensitivity, and adaptive capacity, we employed ethnographic research methods that emphasize emic viewpoints to determine how residents see this form of tourism affecting the resiliency of valued community culture, institutions, and traditional livelihoods. Findings indicate that with purposeful engagement in niche cruise tourism involving boats with 250 passengers or less, and an active rejection of the large cruise ship industry, Petersburg exhibits increased adaptive capacity to promote the resilience of valued community institutions and heritage. This work draws needed recognition to the diversity of activities that fall under the label of cruise tourism, including the distinct implications of smaller-scale, niche cruise tourism for the resilience of coastal communities. It also highlights the need to capture emic perspectives to understand the politics of community resiliency.
\end{abstract}

Keywords: adaptive capacity; climate change; resident perceptions; livelihoods; Alaska; cruise tourism

\section{Introduction}

Coastal communities will experience a disproportionate amount of biophysical change driven by both anthropogenically induced climate change and growth-driven economic activity, for which coastal governance must ensure that the new forms of economy are compatible with existing human activities [1]. Tourism is a hallmark characteristic of the "Great Acceleration" of anthropogenic impact across the planet [2], and its influence as a driver of social and environmental disturbance in coastal regions is only growing as natural resource-based livelihoods decline [3-5]. The cruise tourism industry, in particular, is often critiqued along these lines as one of the most exploitive forms of tourism for coastal communities (e.g., [6-8]). Yet, little has been written about how the cruise tourism sector affects diverse and cherished values within communities, local-level governance and decision-making, and control over natural resources upon which livelihoods are inextricably linked in coastal contexts.

With a high livelihood dependence on natural resources and productive marine ecosystems [9], coastal communities may have limited means to reduce their exposure and sensitivity to such climatic and ecosystemic disturbances. Engagement in the tourism industry can provide socio-economic stability [10]. However, in some circumstances, tourism itself is a disruptive force that exacerbates economic inequalities, erodes cultural heritage, 
and undermines community institutions. Thus, sometimes for better and sometimes for worse, tourism influences communities, their forms of social organization, and therefore their adaptive capacity necessary to maintain social and economic wellbeing, including resilience, in the face of anthropogenic climate and ecosystem disturbance [11,12]. The nature of a community's relation to tourism is likely dependent on the form of tourism that is dominant in a region and the type of engagement opportunities tourism provides for residents.

Understanding these issues from a residential perspective is essential for fostering resilient and sustainable community development centered on the wellbeing of the diverse populations and ecosystems in the region. The purpose of this research was to conduct a rapid ethnographic assessment of how small-scale cruise tourism is perceived locally and its perceived effects on the resiliency (i.e., exposure, sensitivity, and adaptive capacity) of a destination community in southeast Alaska. As anthropogenic environmental disturbance most influences residents with traditional natural resource-dependent livelihoods, an applied ethnographic approach that seeks to understand resident views, perceptions, social organization, and behavior is critical for determining whether cruise tourism promotes or harms the resilience of local communities.

This research provides several novel contributions. First, theoretically, the current work offers novel contributions by expanding the application of systems thinking and resiliency theory to the analysis of cruise tourism. This framing includes an explicit focus on tourism's impact on resiliency theory's three primary components: exposure, sensitivity, and adaptive capacity. These conceptual distinctions are essential since, as others have noted (e.g., [9] (p. 9)), it can be difficult for local communities to influence their exposure and sensitivity to anthropogenic disturbance directly; however, "adaptive capacity is perhaps the component of vulnerability most amenable to influence, and may be a useful focus for adaptation planning." For this reason, of particular interest in this study is the residents' adaptive capacity to negotiate broader anthropogenic disturbances and provide resilience in ways that they determine to be favorable over time [10,13-15].

Secondly, the ethnographic nature of this study also provides a valuable methodological complement to the existing cruise tourism literature. An ethnographic approach improves understanding of how systemic disturbance resulting from niche cruises is viewed emically from the viewpoint of community residents. This approach highlights the heterogeneity of opinions within the community regarding the influence of cruise tourism on human-environmental relationships in the region. Third, since large-scale mega-cruise ships (e.g., with 3000 passengers and up) have received the vast majority of the scholarly attention related to cruise tourism $[8,16,17]$, this work provides needed recognition of the diversity of activities that exist under the label of cruise tourism. More specifically, it will differentiate how smaller-scale, niche cruises (e.g., yachts and smaller boats with less than 250 passengers) hold different implications for the resilience of coastal communities.

Finally, tourism-including cruise tourism in the Arctic and sub-Arctic-is often promoted for its ability to contribute to the resilience $[6-8,15,18]$ of favored components of local social-ecological systems [5,10], including tourism systems in Alaska [19]. However, in contrast to such endorsements of the cruise sector, other scholarly perspectives are more guarded and often critical regarding the benefits of the cruise tourism sector for local community wellbeing (e.g., $[15,18]$ ). Moreover, sustainable tourism advocates outside of academia are even more critical of the cruise sector (e.g., [20]), characterizing it as one of the most exploitive forms of tourism. With climate change shifting tourism's geographic distribution in Alaska and its continuing promotion as a potential alternative to more vulnerable extraction-based livelihoods, the present inquiry is a timely effort to reconcile these scholarly and practitioner-based perspectives on cruise tourism in the region. Through qualitative recognition of the subjective view of residents regarding cruise tourism's influence on the vulnerability and resilience of local coastal communities, including their positions on how this form of tourism impacts exposure, sensitivity, and adaptive capacity in light of ongoing anthropogenic change, this research provides a 
needed empirical assessment of cruise tourism's ability to live up to its promoted potential to increase community resilience.

\section{Literature Review}

\subsection{Resilience and Adaptive Capacity}

Resilience is the capacity of a system to absorb a disturbance while retaining the same function, structure and feedback, and identity [21]. Holling [22] introduced the concept to understand and measure the capacity of ecological systems to persist in their original state after a disturbance. Scholars have increasingly applied resilience thinking to social systems, with recent definitions acknowledging the ability of communities to adapt to external disturbances towards a more desirable trajectory as a critical component of resilience (e.g., [23]). However, even as the application of this concept extends from the natural to the social sciences, at its core, resilience thinking remains fixated on the amount of shock that may cause systems to shift from one set of conditions to an alternative set of processes and structures [21].

The integrated socio-ecological system approach to resilience dictates that societies and cultures are embedded within the biosphere. Thus, socio-cultural influences shape ecosystems from local to global scales and from the past to the future [21]. Therefore, communities form part of socio-ecological systems and are likewise vulnerable to change, but they can also be influenced by the individuals that comprise them [24]. The resilience literature also emphasizes the concepts of exposure, sensitivity, and adaptive capacity $[21,23,25]$. Exposure is the extent that a system is stressed by the environment, whereas sensitivity is the degree to which the stress affects a system [9]. A system can therefore have a high degree of exposure but exhibits no change due to low sensitivity. A highly sensitive system, in contrast, would be modified with only a small amount of exposure.

Adaptive capacity has been considered as a uniting element between resilience and vulnerability. It refers to the capacity to respond to disturbance and remain in the desired state [26]. Adaptation is the process of deliberate change either in anticipation or in reaction to stress and has significant overlap with resilience thinking [21,27]. A resilience framing allows for an understanding of systems where community-level decision-makers may play a direct role in changing the identity and functionality of the system [12]. Understanding such outcomes requires an epistemological shift in the focus of resilience research to better account for political, historical, and cultural meanings inherent within systems [28]. On such issues, ethnographic social science can yield insights. This research design forefronts residents' emic views of resilience. These views contrast with the etic outlook of socioecological system scientists, who often favor quantitative indicators of socio-ecological system dynamics. For this reason, the concepts of emphasis within resilience literature have shifted over recent decades from quantifiable indicators to more nuanced views of objective, subjective, relational, and cross-scale perspectives [21].

Community resilience is further defined as the "existence, development, and engagement of community resources by community members to thrive in an environment characterized by change, uncertainty, unpredictability, and surprise" [29] (p. 402). The dearth of work in this area can be noted in the competing interpretations of adaptive capacity in relation to other key concepts. For example, some definitions of community resilience emphasize the ability to adjust to a disturbance, minimize harm, utilize new opportunities, and cope with the consequences of a transformation $[25,30]$. Yet, other definitions are more socially focused, acknowledging specific human actions taken to improve resilience $[12,31,32]$. This latter approach to addressing adaptive capacity has been further differentiated as social adaptive capacity.

McClanahan and Cinner [12] (p. 72) offer an operational definition of adaptive capacity that embraces its social components, defining it as "the conditions that enable people to (1) anticipate and respond to change, (2) minimize and recover from the consequences of change, and (3) take advantage of new opportunities." It refers to the social means to reduce vulnerability and increase the resilience of individuals, social institutions, and communities 
to system shocks and stresses [33]. Most studies focusing on the social elements of adaptive capacity have focused on coastal and fishing communities [33], creating a well-suited opportunity to explore the influence of other livelihood strategies such as niche cruise tourism. Table 1 summarizes the key concepts related to community resiliency.

Table 1. Key Conceptual definitions.

\begin{tabular}{cl}
\hline Exposure & $\begin{array}{l}\text { "The nature and degree to which a system experiences environmental } \\
\text { or socio-political stress" [34] (p. 270); "the extent to which a region, } \\
\text { resource, or community experiences change" [9] (p. 2) }\end{array}$ \\
"The degree to which a system is modified or affected by \\
perturbations" [34] (p. 270); "the susceptibility of a defined \\
component of the system to harm, resulting from exposure to \\
stresses" [9] (p. 2) \\
"The ability of a system to evolve in order to accommodate \\
environmental hazards or policy change and to expand the range of \\
variability with which it can cope" [34] (p. 270); "the conditions that \\
enable people to (1) anticipate and respond to change, (2) minimize \\
and recover from the consequences of change, and (3) take advantage \\
of new opportunities" [12] (p. 72)
\end{tabular}

\subsection{Tourism and Community Resilience in Uncertain Times}

Resilience theory offers several conceptual tools for understanding how humanenvironment systems respond to, and potentially bounce back from, anthropogenic disturbances [21,30,34]. This theory brings a critical theoretical lens to bear on studies of tourism's impacts. Yet despite an academic history dating to the 1970s (e.g., [22]), the potential for resilience framings and related socio-ecological system science to bring an improved understanding of when and where tourism contributes to social and environmental wellbeing is only just beginning to be embraced by tourism scholars. Scholarly attention to resiliency theory in tourism studies picked up steam in the 2010s. This delayed explosion of interest in resiliency theory among tourism scholars has produced content that is too extensive to review here thoroughly (we direct interested readers to [13,15,18,35-37]). Suffice to say, two trends are worth noting concerning this emerging scholarship.

First, the dominant approach to resiliency in tourism scholarship has emphasized responses of the tourism industry to climate change (e.g., [10,35,37-40]) or to natural and unnatural disasters (e.g., [41,42]). Much rarer is writing that critically assesses tourism as a significant anthropogenic disturbance affecting the resiliency of traditional livelihoods, culture, community institutions, power dynamics, justice, and equity issues. Much of the prior work is thus failing to capture the "politics of resiliency," that is, the issues of power, justice, and equity inherent in any effort to account for community resiliency $[15,36,43,44]$. The need to research community responses to long-term structural changes, including those resulting from various forms of tourism development, is finally gaining traction in recent years $[15,18,24]$, though more need for this kind of work exists.

Second, few scholars thoroughly apply all the theoretical tools of resiliency theory (e.g., analyses of exposure, sensitivity, and adaptive capacity) in their analyses of tourism. Empirical research of the specific way tourism influences adaptive capacity in destination communities thus remains needed to help tourism planners overcome vulnerabilities and create resilience-building solutions $[15,45]$. Deepening our understanding of tourism's influence on the adaptive capacity of local communities, and thus their ability to regulate 
their exposure and sensitivity to anthropogenic change, is a promising path toward a more sustainable management of tourism in all its forms in the future.

\subsection{Cruise Tourism, Communities, and Resiliency}

Although the extent of cruise tourism scholarship has also grown too large to address fully here (interested readers are encouraged to view Dowling and Weeden's [16] edited volume for a wide-ranging overview of current cruise tourism scholarship), resilience theory remains absent in the bulk of this literature. As noted earlier, concerning tourism research more broadly, when cruise tourism scholars invoke resiliency theory, they often do so with regard to improving the resiliency of the cruise industry itself to external anthropogenic changes, such as climate [46,47], disasters [37], and, more recently, COVID$19[48,49]$.

Efforts to assess community and resident perspectives of cruise tourism and its impacts with other theoretical framings do exist (e.g., [50,51]), yet such work has been carried out in survey-based approaches. Such one-off snapshots do little to account for temporal aspects of community history, tourism's influence on local institutions over time, emic views of residents, or other insights into community resiliency. Where interview-based research on resident views of cruise exists, it has been conducted by former and current cruise industry representatives and with methods that exhibit much in the way of inherent confirmation bias regarding favorable outcomes of cruise tourism [52]. Other applied research has been more critical, providing valuable insights into community impacts [20]. In no instance has cruise tourism research been framed in terms of impacts on exposure, sensitivity, or adaptive capacity, each of which is a foundational concept in the resiliency theory initially conceived by ecologists.

Furthermore, there also remains little recognition of the ways that cruise tourism operates at different scales. For instance, how do impacts of micro/boutique/niche cruises with less than 250 passengers differ from those of massive mega-cruise ships that hold $5000+$ passengers? Unmistakably, such distinct forms of cruise tourism results in different outcomes in destination communities [16]. Thus, it is clear that recognizing variability within the cruise sector and addressing the corresponding variability in its social and environmental impacts and outcomes for destination communities is central to any efforts to increase responsibility within the cruise tourism sector and to improve outcomes for destination residents [6].

Given that the writing tends to situate cruise tourism at the more socially and environmentally disruptive end of the spectrum of anthropogenic impact, there is an opportunity to apply the tools of resiliency theory to examine cruise tourism itself as a primary driver of anthropogenic disturbance in destination communities. To better account for the "politics of resiliency," this opportunity must bring the conceptual tools of resilience theory (e.g., adaptive capacity) and the insights provided by ethnographic research approaches (e.g., emic perspectives of residents) to bear on the analysis of the impacts of cruise tourism on the resilience of coastal destination communities.

\subsection{Research Question}

The overarching objective of the current research is to explicitly address the relationship between resilience and tourism in a coastal Alaskan community where niche cruises (i.e., boats with 250 passengers or less) are popular. More specific objectives include analyzing residents' emic views of how they have organized to confront climatic, environmental, and tourism-related management challenges to promote overall community resiliency and wellbeing. In light of the still-limited empirical attention to the concept of adaptive capacity in the literature on sustainable tourism, a further objective is to parse out tourism's distinct influences on exposure, sensitivity, and adaptive capacity of cruise tourism destination communities. By paying particular attention to adaptive capacity as the concept "most amenable to influence" and of most value for adaptation planning [9] (p. 166), this work accomplishes the final objective of bridging tourism studies with the larger body of resiliency 
literature. With these objectives in mind, the following research question is explored in the remainder of this paper: if and how do existing niche cruises affect the resilience of rural Alaskan communities in the face of anthropogenic climate and ecosystem disturbances? If niche cruises increase community resilience, then within residents' emic views, we would expect to encounter evidence of reduced exposure to systemic environmental changes occurring in the region, decreased sensitivity to these changes, and increased adaptive capacity to adapt to systemic change in ways that promote favored outcomes (Table 1).

\section{Methods}

\subsection{Study Site in Southeast Alaska}

In Southeast Alaska, the Forest Service manages $80 \%$ of the land as part of the Tongass National Forest (TNF), the largest temperate rainforest in the world. Overlapping jurisdictions of the National Park Service, the State of Alaska, local governments, and private owners account for the remaining $20 \%$ of the region's land [53]. In the rural communities of this region, it is widely believed that natural resource wealth is "one of the few means through which a vital economy can be constructed in Alaska is through the extraction of its natural resources" [54] (p. 427). The region's largest private industry has long been fishing and seafood processing, though these sectors have recently declined [53]. Although a drastic decline in the logging sector has resulted in that activity concentrating in just two communities, it continues to have a pervasive influence, as nearly all region's communities reside inside, or directly adjacent to, the TNF [53].

With a decline in extraction-based industries in Southeast Alaska (Figure 1), cruise tourism became more prominent in the community and its household economies, instigating significant change for many towns' economic profiles [55]. Alaska is the top cruise destination in the United States, receiving 3.8 million port-of-call cruise visitors in 2018 [56]. The large cruise ship industry has grown into one of the most potent influences across the southeastern. The southeastern Alaskan towns of Juneau, Ketchikan, and Skagway account for $80 \%$ of these visitors, who come to enjoy the "Inside Passage" tours that weave in and out of the Alaskan panhandle's islands (Figure 1). As it does in coastal regions across the globe, the cruise tourism industry places pressure on coastal communities to serve as ports of call $[6,7,57]$. Despite much-promised development, it remains unclear if cruise tourism yields much opportunity to promote resilience for small coastal communities. To negotiate these changes in ways that preserve community fabric and collective identity, community stakeholders are required to carefully consider the nature and magnitude of cruise tourism they are willing to allow in the region [58].

We carried out the current research in the niche cruise destination community of Petersburg, Alaska. Elements in the broader socio-ecological system of interest in this study including Petersburg itself, the surrounding natural environment upon which most livelihoods depend, the Indigenous populations of Tlingit and Haida who have long utilized the area as their summer fish camp, and the Norwegian settlers who began inhabiting the area in the early 20th century. Fishing, artisanally by indigenous populations and commercially by later immigrants, has always been the critical link between people and the local environment, helping to coin the Petersburg slogan, "a town built by fish".

Atypical of this coastal region, where larger-scale cruise tourism is prevalent, tourism in Petersburg consists primarily of visitation via private yachts and smaller niche cruise ships of less than 250 passengers. The local geography restricts access to larger cruise vessels and maritime ships. Bear hunting, festivals, and fishing lodges attract a limited number of additional visitors via ferryboats and regional flights. While in many ways, Petersburg epitomizes a community undergoing shifts and a diversification of livelihoods beyond natural resource extraction, and its geography has resulted in a distinct niche cruise sector that is unique among other Southeast Alaskan communities. 


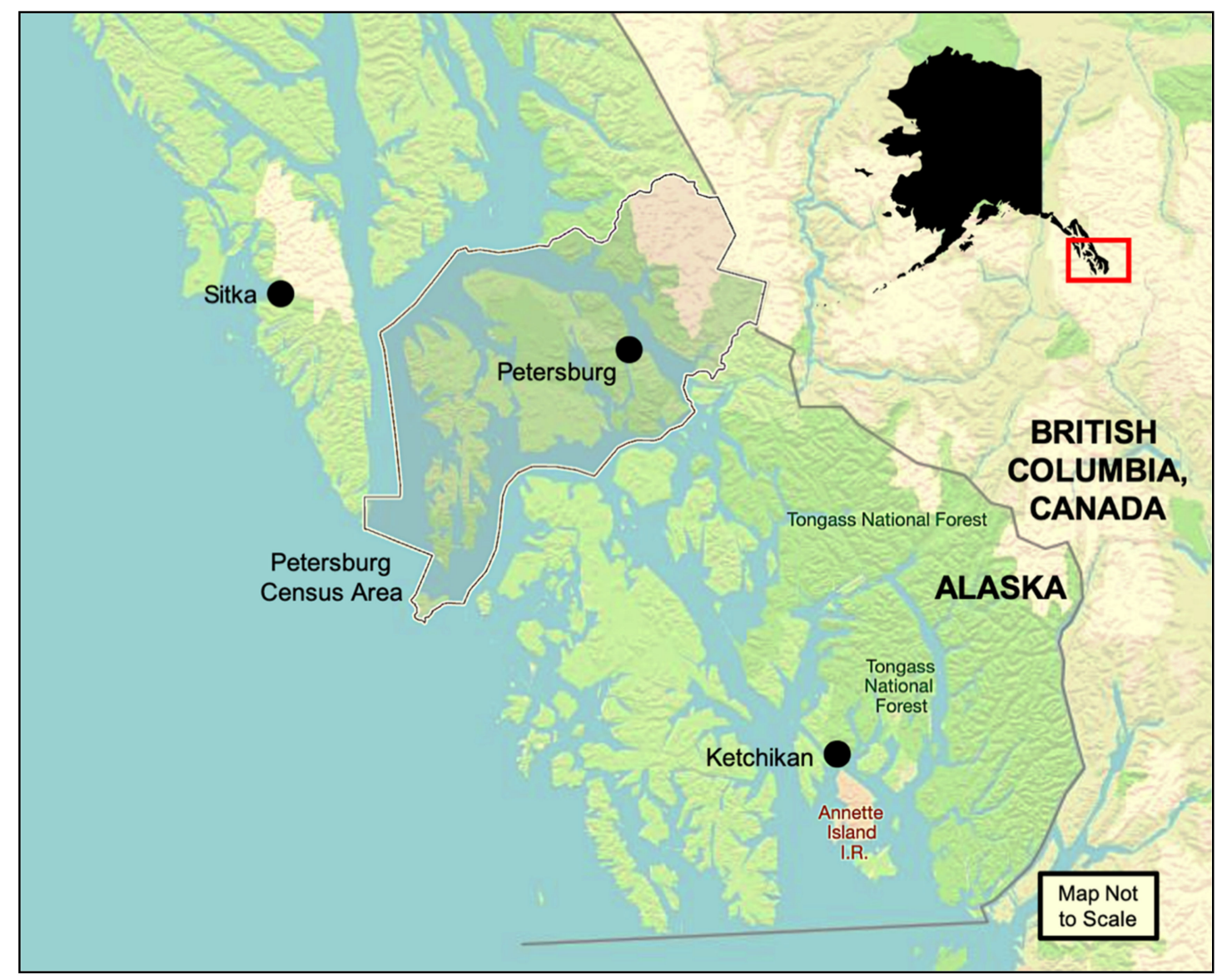

Figure 1. Map of Southeast Alaska showcasing Tongass National Forest (Source: Authors).

\subsection{Ethnographic Research Design}

For this exploratory research seeking to understand the views of rural Alaskan residents, a rapid ethnographic design was carried out [59]. Ethnographic approaches uncover temporal processes and socio-cultural and political dynamics from residents' emic points of view $[60,61]$. Emic viewpoints are of those individuals being studied (in contrast to the etic perspective of researchers stemming from generalized theory [61]). This approach permits the researcher to "explore the beliefs, language, behaviors, and issues such as power, resistance, and dominance" [62]. Ethnographers seek this emic understanding to add nuance to the etic perspectives of the scientific community and to then contribute to broader theory through modifications that better account for the learned emic ideas. These activities are most appropriate for describing processes, the what and how of a culture, and how these are entangled in temporal dynamics and histories in the native, emic point of view $[59,61]$.

Furthermore, though researchers have developed the rapid ethnographic assessment (REA) procedures simultaneously in the fields of rural development and epidemiology [63], they have since been adapted to diverse studies of agriculture and other traditional livelihood practices, and even to research on community reactions to urban park management [64]. REA procedures favor "timely, focused, and qualitative information at the expense of 'scientific' sureness of results through strong probability sampling" [65] (p. 2). REA is carried out by constantly re-evaluating findings as new data is acquired, allowing for further research questions to be generated in the process [63]. This type of applied ethnographic research can provide a great deal of cultural information useful for future planning in a relatively short amount of time $[63,66]$.

In the present study, we seek to understand how coastal Alaskans view the influence of tourism on community resiliency and longer-term sustainable development. To this 
end, several modes of data collection were carried out: multiple forms of ethnographic interviewing, participant observation, and extensive archival data gathering. After obtaining approval from the Internal Review Board for Human Subjects Research in April 2019, fieldwork took place between May and August 2019. All participant observations occurred in public settings, and these observations systematically recorded tourism interactions and exchanges, resident daily lives, and points of convergence between the two, thereby reducing reactivity [59]. In addition, archival data regarding the history of natural and cultural resources in Petersburg and documentation from various local and regional institutions were gathered remotely and on-site between March and November, 2019.

Interviews served as the principal research instrument. A semi-structured interview guide contained core questions for key informants addressing the temporal dynamics of informants' livelihoods, Petersburg's cultural heritage and livelihood history, and the onset of tourism in the community and across the region in recent decades. The content of this initial interview guide evolved during the fieldwork to incorporate knowledge gained through each successive interview $[63,67]$. Twenty-eight semi-structured interviews were conducted, ranging from 26 to $104 \mathrm{~min}$ in length. In total, we collected $33 \mathrm{~h}$ of recorded interviews from 31 informants, including three multi-informant interviews. Interviews were recorded on either an Apple iPhone or a separate digital voice recorder. Interview locations were chosen at the informant's convenience, in places ranging from canning facilities to the borough assembly hall.

We employed various purposive sampling strategies to obtain the most comprehensive emic understandings of the role of cruise tourism on community resilience. Opportunistic sampling occurred initially, though a purposive quota sampling strategy was eventually implemented for the bulk of the semi-structured interviews to capture diverse perspectives of community members across key subpopulations (e.g., those based on the type of livelihood or time spent in the community). Individuals with a long-term presence in Petersburg were sought, given the insight they could provide into temporal changes in the community. Lastly, chain-referral sampling was attempted at the end of each semi-structured interview to identify additional informants with similar cultural expertise.

Throughout the fieldwork, valuable data was also gathered through informal, ad hoc interviews as such opportunities arose. With informal interviews, jot notes of conversations heard throughout the course of the day were recorded and elaborated into field note entries that evening. Both participant observation and informal interviewing helped build rapport, reduce reactivity, and uncover new topics of interest [59]. These data-gathering activities became invaluable in accessing difficult-to-reach populations (e.g., fisherman whose schedules and mobility rarely allowed for formal semi-structured interviewing).

\subsection{Data Analysis}

Archival documents, participant observations, informal interview field notes, and verbatim transcriptions from semi-structured interview recordings were all assembled into a corpus of text that was imported, organized, and analyzed in MAXQDA software. MAXQDA allowed for the efficient organization and ease of retrieving all the data sources. Applied thematic analysis was carried out by first structurally coding the overall corpus of text [67]. Structural coding involves using a content-based or conceptual phrase representing a topic of inquiry to a segment of data that relates to a specific research question used to frame the interview [68] (p. 66). We then proceeded with the following inductive coding techniques: focused coding to develop categories without distracted attention at this time to their properties and dimensions [68] (p. 155); axial coding to relate "categories to subcategories [and] specifies the properties and dimensions of a category" [69] (p. 60); and theoretical coding, link all categories systematically with the central/core category "that appears to have the greatest explanatory relevance" [70] (p. 104). Throughout the process, in vivo coding (i.e., the convention of naming codes with cover terms derived from interviewees' own words) was also incorporated to ensure emic dimensions were maintained during the coding process. In this way, emergent dimensions of resilience were 
grounded in emic understandings of exposure, sensitivity, and adaptive capacity. These coding procedures provide a robust inductive analysis to address the many nuances of the study's research question.

All research is an interpretive and subjective endeavor carried out by and on human beings, though research involving qualitative data and analysis, in particular, relies heavily on interpretation. Nevertheless, several measures can be taken to ensure the validity and trustworthiness of the findings presented here. First of all, the ethnographic approach involved prolonged engagement and persistent observation to develop a baseline understanding of the study community dynamics. As the fieldwork progressed, these strategies, in turn, yielded opportunities for peer-review and debriefing regarding emerging interpretations of the qualitative data [62]. These activities occurred both with members of the community as well as among the author team. The resulting understandings were further validated through triangulation across data from archival sources, participant observation, field note entries, and other informal interviews. This iterative triangulation process began on site and continued in the months following fieldwork. Finally, our use of rich, thick descriptionsincluding numerous vignettes and direct quotations from emic sources-provides other scholars with the means to determine how and where the findings are transferable to other research contexts [62]. Thus, while the overall generalizability of this research cannot be reduced to a numerical value of confidence, as is often the case in quantitative analysis, the findings presented here are theoretically generalizable insomuch as they contribute to a greater understanding of how the cruise tourism sector influences community resilience.

\section{Findings}

We organized the following elaboration of the ethnographic findings around the three foundational components of resiliency theory: exposure, sensitivity, and adaptive capacity.

\subsection{Tourism and Exposure in Petersburg}

Resilience theory suggests that, if tourism increases community resilience, evidence of reduced exposure to systemic environmental change should be evident. Consistent with others, we conceptualize exposure in coastal contexts as "depending on factors such as oceanographic conditions, prevailing winds, and latitude, which can increase the likelihood of being impacted by events such as cyclones or coral bleaching" [9] (p. 2). In other words, local community members often have little ability to directly influence their exposure to such anthropogenic effects that local community members nevertheless often have little ability to influence directly (e.g., [12,23]). After analyzing exposure in Petersburg over time, temporal insights became clear that much socio-political stress has derived from environmental change in other industries. Residents often invoked this history when addressing how cruise tourism has led to changes in the community.

When Alaska experienced its hottest month on record in July 2019 [71], international news coverage fixated on the large-scale salmon die-offs [72]. For residents, it was the first time in memory when the mountains did not have snow cover throughout the summer. Reduced drinking water reservoirs and inadequate stream levels for anadromous salmon inhibited the species' return to its spawning grounds. One fisherman outlined the local population's close relationship to the environmental system:

"Without the rain, the water temperature in the streams was too high. If the water temperature gets too high, the waters not oxygenated. If the waters not oxygenated, the fish would die. It is predicted that in three years we could have a dire fishing season because so many fish that should have escaped up the streams did not get there this year."

This quote exemplifies the intimate knowledge residents hold about the functioning of ecosystems upon which their livelihoods depend. Residents in Petersburg are keenly sensitive to how environmental shocks within the salmon fishery ripple through the local socio-economic system, yet in terms of climate-related disturbances, they also recognize having little local ability to reduce their exposure to such global stressors. 
Residents are likewise acutely tuned to the collapse of other environmentally-linked livelihoods, such as the logging industry [73]. They frequently cited the rapid decline of the logging industry as a shock felt by all residents, including one who noted the following:

"We went through the, I'll call it the environmental movement, of people not wanting any kind of resource management extraction of any sort, whether it be mining, roads, anything. That was quite a shock because it was like jumping into a very hot and jumping into a cold pool, the shock of that going happening almost overnight in about two or three years."

As with climate impacts on local fisheries, the decline of the logging industry, and the resulting loss of livelihood diversity have come to be perceived as resulting from individuals outside the system. Yet, in the case of logging, an additional influence of those who viewed natural resource extraction as an unsustainable industry also led to political pressure to transition away from this economic sector. The community views themselves as having little means to limit their exposure to shifts in these livelihood sectors.

Yet, residents acknowledged how non-extractive economic sectors, including cruise tourism, place stress on local environments. They regarded wastewater pollution as a critical factor inhibiting support, especially among fishers, for scaling up cruise tourism [51]. Wastewater pollution from cruise ships has led to measurable changes in water quality in the region, including in a neighboring community where five beaches were closed in 2019 due to $e$. coli contamination [74]. While it has been suggested outside of Petersburg that the cause was small cruise ships, the residents' emic views distinguish between the impacts of large cruise ships responsible for environmental impacts and those that have a lesser effect (i.e., niche cruises). There is a clear recognition of differences in scale, though residents perceived both forms of cruise tourism as increasing Petersburg's exposure to additional environmental stress.

While representing a shift away from the extraction-based industries that have long characterized this region of coastal Alaska, the cruise tourism industry is nevertheless still associated with the social and economic consequences of increased exposure to environmental hazards. There are strong sentiments that cruise ship activity is creating measurable changes in water quality, with direct implications for what has historically been primary livelihood activities (i.e., fishing) and tourism itself in the future. Concerning community resilience, evidence remains weak that tourism can reduce Petersburg's exposure to anthropogenic disturbance (e.g., climate change) and may instead actually contribute to it (e.g., via wastewater discharge).

\subsection{Tourism and Sensitivity in Petersburg}

As Cinner and others have noted [9] (p. 2), social systems in coastal communities "are more likely to be sensitive to climate change if they are highly dependent on a climatevulnerable natural resource." If tourism increases community resilience, we would therefore expect to find evidence of reduced sensitivity to systemic environmental change over time. For this reason, we first compared how impacts are felt in the resource- and climatedependent commercial fishing industry and then compared how residents see community sensitivities as being affected by recent niche cruise tourism development.

As noted in the town slogan, "a town built by fish," residents have long viewed the community's success as entirely dependent on the success of the fishing industry and the functioning health of the local fisheries' ecosystem. A fish processor further elucidated the importance of fishing in everyday life:

"I'm going out and get my haircut. Then the first question will be, 'have the pink [salmon] showed up yet?' You'd go to the grocery store and you're walking through and you're talking to people whose kids on a boat and 'are they getting any up at Augusta?' I mean we're all talking that language this time of year."

This quote exemplifies the residents' constant awareness of fishery conditions and health, to the point of it being a part of mundane daily conversation. In contrast, residents 
view tourism differently. Cruise arrivals support significant service-based livelihoods via charter agencies, as do other forms of local visitation to bed and breakfasts and hunting/fishing lodges. Yet, such tourism jobs are not seen as "family-wage jobs" in the same way that fishing livelihoods are. Tourism-related employment is recognized as a critical supplementary source of income, though primarily for the younger generation and as a retirement plan for older community members. It is not yet seen as supporting the community as a whole, and there is little sense that it is helping to address sensitivities to anthropogenic disturbances in the fishing and, to a lesser extent, the logging industries.

Indications are that the economic benefits of Petersburg's niche cruise tourism industry are growing and that they are offsetting the heightened sensitivities to the environmental disturbance that many interviewees experience in the fishing sector. Such contributions of tourism will continue to grow in the future. When residents employ the common saying that "one good day during the summer lets us stay open for another week in the winter," they are often juxtaposing the plight of Petersburg to that of other communities. In these communities, stores catering to cruise-base visitors close during the low seasons. Comprised of smaller niche cruises and on-land visits via the ferry system, the nature of tourism in Petersburg not only exhibits less sensitivity than the fishing sector, it also softens the economic oscillation of a fishing-related livelihood's seasonality. Furthermore, the seasonality of tourism in Petersburg is less than in neighboring communities, where larger cruise ship visits dominate tourism-related activities.

There are indications that niche cruise tourism reduces sensitivities to seasonality in relation to fishing-based livelihoods and the large cruise ship sector that characterizes neighboring communities. While fishing remains particularly sensitive to environmental and climatic change, for the time being, residents see smaller-scale niche cruise tourism as reducing Petersburg's overall sensitivity by buffering the impacts of ecological disturbance on the fishing industry. In addition, by diversifying livelihood opportunities beyond the historical dependency on a fishing economy and providing a supplemental economic sector that provisions year-round services for all residents, niche cruise tourism reduces community sensitivity to ongoing environmental change and, as a result, improves overall community resiliency.

\subsection{Tourism and Adaptive Capacity in Petersburg}

According to resiliency scholars, adaptive capacity "is a latent characteristic that reflects peoples' ability to anticipate and respond to changes, and to minimize, cope with, and recover from the consequences of change" [9] (p. 2). If tourism increases community resilience, we would expect to find evidence of the residents' ability to anticipate and respond to changes and to minimize, cope with, and recover from the consequences of change in the face of systemic environmental change. More so than exposure and sensitivity, adaptive capacity is of particular interest in this analysis of community views, as it may be the element of resiliency that most relates to the actions, behaviors, policies, and management strategies that residents can enact $[12,27]$.

Petersburg residents are quick to emphasize that community resiliency revolves around an interest in maintaining the town's fishing-based identity, both in light of changes affecting the fishing industry and the new opportunities provided by tourism. Temporal and geographic displacement, gear diversification, and extension of harvest seasons have all served as adaptive strategies for improving the resilience of fishing-based livelihoods. While a lingering faith in the resiliency of the fishing sector may inhibit the development of adaptive strategies via other sectors, such as niche cruise tourism, residents now see such developments as the inevitable economic consequences of environmental change in the fishing sector.

Community resilience has historically been linked entirely to the local benefits and corresponding livelihood capacity derived from resource extraction. As a result, many residents are concerned that a change away from extraction will result in the loss of the associated community fabric. For instance, a borough council member described the 
ongoing appeal of extractive industries (i.e., fishing and logging): "It is a resource state [Alaska] and a resource town [Petersburg], and without [natural] resources I don't know what you would do. As far as change over time, things will either stay the same, or they will just probably disappear".

Concerns for the loss of such long-held sentiments peaked in response to the closing of Petersburg's largest cannery, Ocean Beauty, in 2018 [75]. One resident described a fear about the longevity of the community's remaining cannery (i.e., Petersburg Fishing Incorporated, PFI): "I think losing that [PFI] would be, you'd take a hit in your hardworking town sort of identity, right?" The resident went on to state how community members view the future: "we've very much been natural resource extraction type town. Really depending on manufacturing, all the things that are having pressure on that. Is that a blip? Is it a trend? Is it climate change, are we going to experience real paradigm shift here?" Residents are keenly aware that the local socio-environmental system is changing. They are anticipating further change, and they question whether changes in the system will retain the same structure and identity - all hallmark concerns of community resiliency.

While doubts remain as to whether this form of tourism is a supplement to the fishingbased economy or if it is to become the primary economic activity itself, faith is slowly growing regarding the ability of well-managed niche cruise tourism to address community resiliency concerns. In 2018, Petersburg implemented a marine passenger fee, called a "Head Tax," resulting in USD 38,000 in new tax revenues in 2019 [76]. State legislation dictated that these revenues benefit maritime shipping, under which the niche cruise industry operates. Currently, only two other regional communities have implemented a similar head tax-Juneau and Ketchikan. Both communities experience tourism on a much larger scale; however, fund appropriation is assessed with caution here. A powerful cruise line filed a lawsuit in Juneau, stating that current spending is unconstitutional. This action resulted in not just a loss of the head tax revenues for Juneau but an additional settlement of USD 1.5 million in favor of the cruise company.

For Petersburg residents, the distinction between large and small-scale cruise tourism is fundamental. Tourism impacts are consistently discussed in relation to what are perceived to be highly unfavorable tourism outcomes in other parts of southeastern Alaska, where large cruise ships dominate. Indeed, even Petersburg planning documents contain such comparative language: "Previous plans have made clear the community supports small scale, small group, and independent visitors, and wants to draw visitors who appreciate that Petersburg's downtown, unlike Juneau or Ketchikan, is still a 'real town,' focused on fishing and local life" [77]. In Petersburg, residents feel there are lessons to be learned from these neighboring communities, and they are less inclined to support the entering into of contractual relationships with large-scale cruise lines.

In implementing the head tax and engaging in niche cruise tourism with a less powerful legal lobby, Petersburg avoids disempowering relationships that neighboring communities have experienced with large cruise ship companies. As a resident describes: "however, we need to do it and learn from our neighboring towns and make sure that there's stipulations in place that the income that the tourists or the cruise ships are getting is as equal to the income the borough receives based on taxes." The niche cruise tourism sector is seen as more manageable. Such directed actions exemplify a new adaptive capacity to maintain community resiliency in the face of shifting economic dynamics.

Shifting attitudes towards tourism are also likewise salient for residents, as the broader regional economy of Southeast Alaska diversifies from an exclusive focus on natural resource extraction to more service-based tourism and recreation industries [55]. The ability for Petersburg to make development decisions based on a shared community identity is seen as an amenity, or a pull factor, for visitors, as described by this resident:

"There was a lot of discussions about like, what makes a town of desirable destination? I think part of it is that we're still a fishing town. That's our industry and I think that a lot of tourists like that because we're functioning, working, got 
canneries and working harbor and people live here year-round instead of just seasonally."

Residents believe that the community's appeal ultimately resides with its authenticity, fishing heritage, and relationship to the local ecological systems. Rather than providing an alternative to the extractive natural resource economy [10], smaller-scale cruise tourism leverages the fishing and logging heritage of the region. It may even leverage the community's history of adapting to change, as alluded to in one resident's comments:

"We talked about the fishing. Where's this global warming taking us? Is there going to be a day sometime when the fish just aren't here? Who knows? Someday in the future, maybe our whole industry, our whole economy is going to be based on tourism. I don't know. But by golly, this town will figure out a way to stay alive."

Economic adaptation into niche cruise tourism, rather than a full-fledged shift (i.e., dependency) to the sizeable mega-cruise tourism seen in neighboring communities, is viewed with optimism as a means of assuring community resilience, particularly when compared to other livelihood alternatives available to residents in the region.

\section{Discussion}

These ethnographic findings suggest that tourism may be limited in its ability to reduce the exposure of Petersburg to larger-scale anthropogenic environmental disturbance (e.g., climate change), and it may only have a marginal capacity to reduce sensitivity to such disturbance $[10,14,78]$. Yet, with purposeful engagement in niche cruise tourism and the active rejection of the larger-scale cruise ship industry, Petersburg is indeed exhibiting the increased adaptive capacity necessary to sustain the resilience of valued community institutions and heritage $[23,30]$. Table 2 summarizes these relative emic views regarding the relative influence of the community's primary livelihood alternatives on community resilience.

Table 2. Characterization of Emic Views of Contributions to Community Resiliency.

\begin{tabular}{ccccc}
\hline & $\begin{array}{c}\text { Commercial } \\
\text { Logging }\end{array}$ & $\begin{array}{c}\text { Commercial } \\
\text { Fishing }\end{array}$ & $\begin{array}{c}\text { Large Scale } \\
\text { Cruises }\end{array}$ & $\begin{array}{c}\text { Niche Cruise } \\
\text { Tourism }\end{array}$ \\
\hline $\begin{array}{c}\text { Reducing Exposure } \\
\text { Reducing Sensitivity } \\
\text { Increasing Adaptive } \\
\text { Capacity }\end{array}$ & + & + & + & + \\
\hline $\begin{array}{c}\text { Notes: + degree of positive influence; }{ }^{*} \text { characterizes neighboring communities; } \\
\text { ** characterizes Petersburg. }\end{array}$
\end{tabular}

Since adaptive capacity is ultimately the ability to reach a desired state [26], understanding the social elements (e.g., human values) within a socio-ecological system is necessary to understand the two "whats" of the question, "the resilience of what, to what?" [21]. This inherent quality of adaptive capacity is even recognized among one Petersburg resident, who stated that: "Just being cognizant of what we want the future of the community to look like and going from there, finding what we can do to make that a reality or to discourage certain realities." The desired state (i.e., the resilience of what to what) can only be defined by the community members themselves [12]. This study captures those emic views.

Much opportunity exists in cruise tourism scholarship, and tourism research more broadly, to go beyond survey-based snapshots with research approaches focused on capturing emic views. Such views are essential for understanding temporal trajectories and capturing valued meanings within destination communities undergoing anthropogenic change, including but not limited to tourism development [79-81]. Although anomalous of the large cruise sector that characterizes Southeast Alaska, the Petersburg example demonstrates that emic views may be particularly valuable to planners and policymakers in destinations that are in the early stages of tourism development $[35,79]$ or where different 
models of (cruise) tourism development are being considered [50]. One additional opportunity to integrate this finding with new tourism policies would be for Petersburg to establish a standing multi-sector advisory board to guide further tourism development policy for the community. Such a board could be responsible for reviewing new tourism-related business proposals to ensure the proper assessment of and adherence to agreed-upon norms for environmental and socio-cultural impacts.

Furthermore, the current work provides key theoretical contributions by elaborating on the distinct impacts created by large-scale mega-cruise ships with 3000 or more passengers and the smaller-scale, niche forms of cruise tourism, involving yachts and smaller boats with under 250 passengers. These dramatically different forms of cruise tourism hold distinct implications for the resilience of coastal communities, and both tourism scholars and policymakers would be wise to distinguish between them more carefully, as opposed to lumping them together under a single, reductionistic umbrella term (e.g., cruise tourism). Additionally, regional policymaking would benefit from a broader assembly of community advisory boards into a regional board comprised of representatives from each community. A regional planning body of this nature would greatly assist with new and ongoing tourism planning across the region to better manage how and where small- and large-scale cruise tourism is most suitably developed.

This study also demonstrates another value of the ethnographic approach to assessing community resiliency. While in Petersburg, the faith in the adaptive capacity of the fishing economy remains high, though recognition is growing of the adaptive strategies available through tourism development, which can also be viable if tourism helps perpetuate the longstanding culture of the community. Culture is increasingly recognized as an essential component of socio-ecological systems [21], as it is critical for system memory, identity, and function. For this reason, resiliency scholars have noted that "cultural factors shape how people support adaptation interventions, and their motivation to respond to them" [11] (p. 115). Thus, tourism scholars and policymakers are encouraged to better recognize the cultural influence on community resilience and tourism's role in that relationship. Ethnographic methods are best suited to capturing these shared cultural aspects of resiliency in anthropogenic and tourism-related changes, including those resulting from the arrival of the cruise industry in new destinations [82]. Given the centrality of fishing to the culture of Petersburg, policies that direct tourism development grants to individuals in the fishing community would have significant benefits. First, such grants would help ensure that the fishing community leads the charge on new tourism initiatives based on the most treasured heritage. Secondly, such grants would also help diversify the economic portfolios of individuals in the fishing industry, thereby increasing their adaptive capacity to future economic and environmental disturbances.

Finally, the findings presented above justify more application of system thinking in cruise tourism studies. Specific "systems thinking" approaches to assess cruise tourism have been nearly absent in the literature. One recent exception explored the sustainability of cruise tourism in the context of World Heritage Sites [17]. Yet, the need remains to bring the systems perspective that characterizes resiliency research to bear on cruise tourism more broadly. Such work will essentially be mandatory in many cruise tourism destinations if the industry is to exhibit resiliency to future economic, climatic, or pandemic-related disturbances in the future.

\section{Limitations}

There are inherent limitations with both the theory and methodology used in this study. First, resilience research at the community scale is inherently contextual as the driver of resilience and vulnerability are based upon the socio-ecological system upon which communities are embedded [21,45]. The capabilities of Petersburg are therefore different from any other resilience context. Additionally, as this research aimed to gather an idiographic understanding of the various impacts of tourism on a community's resilience to systemic environmental change, this research describes multiple means through which 
tourism influences exposure, sensitivity, and adaptive capacity were affected by tourism specifically in Petersburg. Extending our methodology, future quantitative study could seek to confirm these findings nomothetically, establishing effect sizes, and thus more readily compare outcomes regarding resilience and adaptive capacity indicators in Petersburg, communities in southeastern Alaska, and the broader Alaskan region.

Nevertheless, this research is timely. The COVID-19 pandemic has created the shock necessary to analyze system reorganization-or lack of - as cruise visitor volume in Alaska dropped from 1.33 million in 2019 to zero visitors in 2020, leaving communities "hanging by a thread" or in "complete devastation" from the lack of tourism [83]. This shock has highlighted unforeseen system variables such as the relationship between cruise tourism and public safety [84]. Yet, the pandemic has also underscored the differences within the cruise sector, where ships with less than 100 passengers are still able to travel through Canadian waters and are seeing an increased demand [85]. This research has contributed to a better understanding of the differences within the cruise tourism sector via the three primary components of resilience. Opportunities remain to explore the extent of these differences. Future research should address how community resilience differs across the region due to its dependency on different forms of cruise tourism.

\section{Conclusions}

Both resilience (e.g., of what to what) and adaptive capacity are terms that depend on the subjective valuation of the systems of interest, and this subjectivity ultimately defines what the desired state of the socio-ecological systems should be. This study sought to understand the emic views of how the desired type and quality of community conditions in Petersburg are affected by the primary form of tourism-niche cruises. Residents are aware that exposure and sensitivity to the environmental disturbances affecting traditional extraction-based livelihoods (e.g., logging and fishing) may require the shifting of adaptation strategies $[9,27]$.

One adaptive strategy for this community has been to reject forms of tourism that erode community identity and fishing-focused culture. Residents instead favor small-scale niche cruise tourism. Should niche cruise tourism develop in ways that continue to bring about the desired outcomes for the community, it will support community resiliency by fostering "the existence, development, and engagement of community resources by community members to thrive in an environment characterized by change, uncertainty, unpredictability, and surprise" [29] (p. 402). This study strongly suggests that not all forms of cruise tourism are created equal, a critical distinction that may enable the improved development, management, sustainability, and resiliency of the cruise tourism sector in the future [45]. By understanding the "lived experiences" of local communities, this research demonstrates the value of ethnographic research in understanding the dynamics of cruise tourism development in destination communities where resident identity is intricately tied to the sustainability of the natural environment, such as in this "town built by fish".

Author Contributions: Several authors made the broadest range of different contributions. Conceptualization, R.S.N. and C.A.H.; Methodology, R.S.N.; Software, R.S.N.; Formal analysis, R.S.N., C.A.H., K.S.Z. and B.D.T.; Investigation, R.S.N.; Data curation, R.S.N. and C.A.H.; Writing-original draft, R.S.N. and C.A.H.; Writing-review and editing, R.S.N., C.A.H., K.S.Z. and B.D.T.; Visualization, R.S.N. and C.A.H.; Supervision, C.A.H.; Project administration, R.S.N. and C.A.H.; Funding acquisition, R.S.N. and C.A.H. All authors have read and agreed to the published version of the manuscript.

Funding: This research was funded by M.G. Whiting Research Award of Inter-Institutional Center for Indigenous Knowledge at Penn State University.

Institutional Review Board Statement: The study was conducted according to the guidelines of the Declaration of Helsinki, and approved by the Institutional Review Board of Penn State University (STUDY00011870, 11 June 2019).

Informed Consent Statement: Informed consent was obtained from all subjects involved in the study. 
Data Availability Statement: The data presented in this study are available on request from the corresponding author. The data are not publicly available due to ethical restrictions and privacy concerns regarding participant consent process.

Acknowledgments: The authors of this article would like to thank the collaboration of the community of Petersburg, Alaska, for their help in carrying out this research.

Conflicts of Interest: The authors declare no conflict of interest.

\section{References}

1. Bindoff, N.L.; Cheung, W.W.L.; Kairo, J.G.; Aristegui, J.; Guinder, V.A.; Hallberg, R.; Hilmi, N.; Jiao, N.; Karim, M.S.; Levin, L.; et al. Changing Ocean, Marine Ecosystems, and Dependent Communities. In IPCC Special Report on the Ocean and Cryosphere in a Changing Climate; 2019; pp. 447-588. Available online: https:/ /www.ipcc.ch/srocc/download/ (accessed on 7 June 2021).

2. Steffen, W.; Broadgate, W.; Deutsch, L.; Gaffney, O.; Ludwig, C. The trajectory of the anthropocene: The great acceleration. Anthr. Rev. 2015, 2, 81-98. [CrossRef]

3. Lenzen, M.; Sun, Y.Y.; Faturay, F.; Ting, Y.P.; Geschke, A.; Malik, A. The carbon footprint of global tourism. Nat. Clim. Chang. 2018, 8, 522-528. [CrossRef]

4. Papageorgiou, M. Coastal and marine tourism: A challenging factor in Marine Spatial Planning. Ocean Coast. Manag. 2016, 129, 44-48. [CrossRef]

5. Bennett, N.J.; Dearden, P. Why local people do not support conservation: Community perceptions of marine protected area livelihood impacts, governance and management in Thailand. Mar. Policy 2014, 44, 107-116. [CrossRef]

6. Klein, R.A. Responsible Cruise Tourism: Issues of Cruise Tourism and Sustainability. J. Hosp. Tour. Manag. 2011, 18, 107-116. [CrossRef]

7. Weaver, D.B.; Lawton, L.J. The cruise shorescape as contested tourism space: Evidence from the warm-water pleasure periphery. Tour. Manag. Perspect. 2017, 24, 117-125. [CrossRef]

8. Weeden, C.; Klein, R.A. Introduction to special issue on cruise tourism. Tour. Mar. Environ. 2018, 13, 189-192. [CrossRef]

9. Cinner, J.E.; Huchery, C.; Darling, E.S.; Humphries, A.T.; Graham, N.A.J.; Hicks, C.C.; Marshall, N.; McClanahan, T.R. Evaluating social and ecological vulnerability of coral reef fisheries to climate change. PLoS ONE 2013, 8, e74321. [CrossRef] [PubMed]

10. Heslinga, J.H.; Groote, P.; Vanclay, F. Using a social-ecological systems perspective to understand tourism and landscape interactions in coastal areas. J. Tour. Futures 2017, 3, 23-38. [CrossRef]

11. Adger, W.N.; Barnett, J.; Brown, K.; Marshall, N.; O'Brien, K. Cultural dimensions of climate change impacts and adaptation. Nat. Clim. Chang. 2013, 3, 112-117. [CrossRef]

12. McClanahan, T.R.; Cinner, J. Adapting to a Changing Environment: Confronting the Consequences of Climate Change; Oxford University Press: New York, NY, USA, 2011; ISBN 9780199754489.

13. Becken, S. Developing a framework for assessing resilience of tourism sub-systems to climatic factors. Ann. Tour. Res. 2013, 43, 506-528. [CrossRef]

14. Ruiz-Ballesteros, E. Social-ecological resilience and community-based tourism. An approach from Agua Blanca, Ecuador. Tour. Manag. 2011, 32, 655-666. [CrossRef]

15. Cheer, J.M.; Lew, A.A. Tourism, Resilience and Sustainability: Adapting to Social, Political and Economic Change; Routledge: London, UK, 2017; ISBN 1315464039.

16. Dowling, R.; Weeden, C. Cruise Ship Tourism, 2nd ed.; CABI: Wallingford, UK, 2017; ISBN 978-1780646084.

17. Cerveny, L.K.; Miller, A.; Gende, S. Sustainable Cruise Tourism in Marine World Heritage Sites. Sustainability $2020,12,611$. [CrossRef]

18. Lew, A.A.; Cheer, J.M. Tourism Resilience and Adaptation to Environmental Change: Definitions and Frameworks; Routledge: London, UK, 2017; ISBN 1315463954.

19. Jordan, E.J.; Vogt, C.A.; Kruger, L.E.; Grewe, N. The interplay of governance, power and citizen participation in community tourism planning. J. Policy Res. Tour. Leis. Events 2013, 5, 37-41. [CrossRef]

20. Ettenger, K.; Hogenson, S.; Honey, M. Marine Tourism, Climate Change, and Resilience in the Caribbean, Volume II: Recreation, Yachts, and Cruise Ships; The Center for Responsible Travel/Business Expert Press: Washington, DC, USA, 2018 ; ISBN 1631577522.

21. Folke, C. Resilience. In Oxford Research Encyclopedia of Environmental Science; Oxford University Press: New York, NY, USA, 2016; pp. 1-60. [CrossRef]

22. Holling, C.S. Resilience and Stability of Ecological Systems. Annu. Rev. Ecol. Syst. 1973, 4, 1-23. [CrossRef]

23. Adger, W.N. Social and ecological resilience: Are they related? Prog. Hum. Geogr. 2000, 24, 347-364. [CrossRef]

24. Bec, A.; McLennan, C.L.; Moyle, B.D. Community resilience to long-term tourism decline and rejuvenation: A literature review and conceptual model. Curr. Issues Tour. 2016, 19, 431-457. [CrossRef]

25. Gallopín, G.C. Linkages between vulnerability, resilience, and adaptive capacity. Glob. Environ. Chang. 2006, 16, $293-303$. [CrossRef]

26. Engle, N.L. Adaptive capacity and its assessment. Glob. Environ. Chang. 2011, 21, 647-656. [CrossRef] 
27. Ferro-Azcona, H.; Espinoza-Tenorio, A.; Calderón-Contreras, R.; Ramenzoni, V.C.; de las Gómez País, M.M.; Mesa-Jurado, M.A. Adaptive capacity and social-ecological resilience of coastal areas: A systematic review. Ocean Coast. Manag. 2019, $173,36-51$. [CrossRef]

28. Cote, M.; Nightingale, A.J. Resilience thinking meets social theory: Situating social change in socio-ecological systems (SES) research. Prog. Hum. Geogr. 2012, 36, 475-489. [CrossRef]

29. Magis, K. Community resilience: An indicator of social sustainability. Soc. Nat. Resour. 2010, 23, 401-416. [CrossRef]

30. Berkes, F.; Ross, H. Community Resilience: Toward an Integrated Approach. Soc. Nat. Resour. 2013, 26, 5-20. [CrossRef]

31. Zimmerer, K.S.; de Haan, S.; Jones, A.D.; Creed-Kanashiro, H.; Tello, M.; Amaya, F.P.; Carrasco, M.; Meza, K.; Tubbeh, R.M.; Nguyen, K.T.; et al. Indigenous Smallholder Struggles in Peru: Nutrition Security, Agrobiodiversity, and Food Sovereignty amid Transforming Global Systems and Climate Change. J. Lat. Am. Geogr. 2020, 19, 74-111. [CrossRef]

32. Zimmerer, K.S.; de Haan, S.; Jones, A.D.; Creed-Kanashiro, H.; Tello, M.; Carrasco, M.; Meza, K.; Plasencia Amaya, F.; Cruz-Garcia, G.S.; Tubbeh, R.; et al. The biodiversity of food and agriculture (Agrobiodiversity) in the anthropocene: Research advances and conceptual framework. Anthropocene 2019, 25, 100192. [CrossRef]

33. Bennett, N.J.; Dearden, P.; Murray, G.; Kadfak, A. The capacity to adapt?: Communities in a changing climate, environment, and economy on the northern Andaman coast of Thailand. Ecol. Soc. 2014, 19. [CrossRef]

34. Adger, W.N. Vulnerability. Glob. Environ. Chang. 2006, 16, 268-281. [CrossRef]

35. Butler, R.W. Tourism and Resilience; CABI: Oxfordshire, UK, 2017; ISBN 1780648332.

36. Cheer, J.M.; Milano, C.; Novelli, M. Tourism and community resilience in the Anthropocene: Accentuating temporal overtourism. J. Sustain. Tour. 2019, 27, 554-572. [CrossRef]

37. Hall, C.M.; Prayag, G.; Amore, A. Tourism and Resilience: Individual, Organisational and Destination Perspectives; Channel View Publications: Bristol, UK, 2017; ISBN 1845416325.

38. Kutzner, D. Environmental change, resilience, and adaptation in nature-based tourism: Conceptualizing the social-ecological resilience of birdwatching tour operations. J. Sustain. Tour. 2019, 27, 1142-1166. [CrossRef]

39. Guo, Y.; Zhang, J.; Zhang, Y.; Zheng, C. Catalyst or barrier? The influence of place attachment on perceived community resilience in tourism destinations. Sustainability 2018, 10, 2347. [CrossRef]

40. Guo, Y.; Zhang, J.; Zhang, Y.; Zheng, C. Examining the relationship between social capital and community residents' perceived resilience in tourism destinations. J. Sustain. Tour. 2018, 26, 973-986. [CrossRef]

41. Lin, Y.; Kelemen, M.; Tresidder, R. Post-disaster tourism: Building resilience through community-led approaches in the aftermath of the 2011 disasters in Japan. J. Sustain. Tour. 2018, 26, 1766-1783. [CrossRef]

42. Kato, K. Debating sustainability in tourism development: Resilience, traditional knowledge and community: A post-disaster perspective. Tour. Plan. Dev. 2018, 15, 55-67. [CrossRef]

43. Lebel, L.; Anderies, J.M.; Campbell, B.; Folke, C.; Hatfield-Dodds, S.; Hughes, T.P.; Wilson, J. Governance and the capacity to manage resilience in regional social-ecological systems. Ecol. Soc. 2006, 11, 19. [CrossRef]

44. Biermann, M.; Hillmer-Pegram, K.; Knapp, C.N.; Hum, R.E. Approaching a critical turn? A content analysis of the politics of resilience in key bodies of resilience literature. Resilience 2016, 4, 59-78. [CrossRef]

45. Calgaro, E.; Lloyd, K.; Dominey-Howes, D. From vulnerability to transformation: A framework for assessing the vulnerability and resilience of tourism destinations. J. Sustain. Tour. 2014, 22, 341-360. [CrossRef]

46. Lamers, M.; Amelung, B. Climate change and its implications for cruise tourism in the polar regions. In Cruise Tourism in Polar Regions: Promoting Environmental and Social Sustainability? Luck, M., Maher, P.T., Stewart, E.J., Eds.; Earthscan: London, UK, 2010; pp. $147-162$.

47. Stewart, E.J.; Dawson, J.; Johnston, M. Risks and opportunities associated with change in the cruise tourism sector: Community perspectives from Arctic Canada. Polar J. 2015, 5, 403-427. [CrossRef]

48. Radic, A.; Law, R.; Lück, M.; Kang, H.; Ariza-Montes, A.; Arjona-Fuentes, J.M.; Han, H. Apocalypse now or overreaction to coronavirus: The global cruise tourism industry crisis. Sustainability 2020, 12, 6968. [CrossRef]

49. Renaud, L. Reconsidering global mobility-distancing from mass cruise tourism in the aftermath of COVID-19. Tour. Geogr. 2020, 22, 679-689. [CrossRef]

50. Jordan, E.J.; Vieira, J.C.; Santos, C.M.; Huang, T.-Y. Do residents differentiate between the impacts of tourism, cruise tourism, and Airbnb tourism? J. Sustain. Tour. 2020, 1-19. [CrossRef]

51. Jordan, E.J.; Vogt, C.A. Residents' Perceptions of Stress Related to Cruise Tourism Development. Tour. Plan. Dev. 2017, 14, 527-547. [CrossRef]

52. McCaughey, R.; Mao, I.; Dowling, R. Residents' perceptions towards cruise tourism development: The case of Esperance, Western Australia. Tour. Recreat. Res. 2018, 43, 403-408. [CrossRef]

53. Kruger, L. Community and landscape change in southeast Alaska. Landsc. Urban Plan. 2005, 72, 235-249. [CrossRef]

54. Sherval, M. Native Alaskan engagement with social constructions of rurality. J. Rural Stud. 2009, 25, 425-434. [CrossRef]

55. Cerveny, L.K. Preliminary Research Findings from a Study of the Socio-Cultural Effects of Tourism in Haines, Alaska; US Forest Service: Portland, OR, USA, 2004.

56. CLIA Alaska Destination: Alaska. Available online: https://akcruise.org/cruising-in-alaska/overview/ (accessed on 7 June 2021). 
57. Adams, A.W. Planning for Cruise Ship Resilience: An Approach to Managing Cruise Ship Impacts in Haines, Alaska. Coast. Manag. 2010, 38, 654-664. [CrossRef]

58. Kruger, L.; Mazza, R. Alaska Communities and Forest Environments: A Problem Analysis and Research Agenda; US Forest Service: Portland, OR, USA, 2006.

59. Bernard, H.R. Research Methods in Anthropology: Qualitative and Quantitative Approaches; Rowman \& Littlefield: Lanham, MD, USA, 2017; ISBN 1442268867.

60. Bernard, R.; Gravlee, C. Handbook of Methods in Cultural Anthropology; Rowman \& Littlefield: Lanham, MD, USA, 2015.

61. Spradley, J.P. The Ethnographic Interview; Holt, Rinehart and Winston, Inc.: Orlando, FL, USA, 1979; ISBN 0030444969.

62. Creswell, J.W. Qualitative Inquiry and Research Design: Choosing among Five Approaches, 3rd ed.; Sage Publications: Thousand Oaks, CA, USA, 2013; ISBN 1506330193.

63. Harris, K.J.; Jerome, N.W.; Fawcett, S.B. Rapid assessment procedures: A review and critique. Hum. Organ. 1997, 56, 375-378. [CrossRef]

64. Taplin, D.H.; Scheld, S.; Low, S.M. Rapid ethnographic assessment in urban parks: A case study of Independence National Historical Park. Hum. Organ. 2002, 61, 80-93. [CrossRef]

65. Manderson, L. Population and Reproductive Health Programmes: Applying Rapid Anthropological Assessment Procedures; United Nations Population Fund: New York, NY, USA, 1997.

66. Leibow, E. Social Impact Assessment. Cult. Resour. Manag. Bull. 1987, 10, 16-19.

67. Guest, G.; MacQueen, K.; Namey, E. Applied Thematic Analysis; Sage Publications: Thousand Oaks, CA, USA, 2012; ISBN 9781412971676 .

68. Saldaña, J. The Coding Manual for Qualitative Researchers, 1st ed.; Sage Publications: Thousand Oaks, CA, USA, 2009; ISBN 9781847875488.

69. Charmaz, K. Constructing Grounded Theory: A Practical Guide through Qualitative Analysis; Sage: Thousand Oaks, CA, USA, 2006; ISBN 144620040X.

70. Corbin, J.; Strauss, A. Basics of Qualitative Research: Techniques and Procedures for Developing Grounded Theory, 3rd ed.; Sage Publications: Thousand Oaks, CA, USA, 2008; ISBN 1483315681.

71. Leslie, J. Alaska Had Its Hottest Month on Record in July. Available online: https:/ /www.noaa.gov/news/alaska-had-its-hottestmonth-on-record-in-july (accessed on 6 April 2020).

72. Perrone, A. Unprecedented Heatwave "Kills Thousands of Fish" in Alaska. Available online: https://www.independent.co.uk/ environment/alaska-heatwave-salmon-rivers-july-temperatures-climate-change-a9063461.html (accessed on 6 April 2020).

73. Sisk, J. The Southeastern Alaska Timber Industry: Historical Overview and Current Status. In The Coastal Forests and Mountains Ecoregion of Southeastern Alaska and the Tongass National Forest: A Conservation Assessment and Resource Synthesis; Schoen, J.W., Dovichin, E., Eds.; The Nature Conservancy: Anchorage, AK, USA, 2007; pp. 1-20.

74. Resneck, J. DEC Issues Warning for Ketchikan Area Beaches. Available online: https://www.krbd.org/2019/06/17/dec-issueswarning-for-ketchikan-area-beaches / (accessed on 10 March 2020).

75. Viechnicki, J. Ocean Beauty Permanently Closes Petersburg Cannery. Beauty Seafoods Will Permanently, Capacity to Meet Customer Demand. Available online: https:/ /www.ktoo.org/2018/08/07/ocean-beauty-permanently-closes-petersburg-cannery/\#: $\sim\{\}:$ text=Ocean (accessed on 28 March 2020).

76. Viechnicki, J. Petersburg's Passenger Fee Nets \$38k in First Year. Available online: https://www.kfsk.org/2019/10/23 / petersburgs-passenger-fee-nets-38k-in-first-year/ (accessed on 10 March 2020).

77. Agnew Beck; Moffat and Nichol; Northern Economics. Petersburg Borough Comprehensive Plan Update; Petersburg Borough: Petersburg, AK, USA, 2016.

78. Espiner, S.; Becken, S. Tourist towns on the edge: Conceptualising vulnerability and resilience in a protected area tourism system. J. Sustain. Tour. 2014, 22, 646-665. [CrossRef]

79. Hunt, C.A.; Stronza, A.L. Stage-based tourism models and resident attitudes towards tourism in an emerging destination in the developing world. J. Sustain. Tour. 2014, 22, 279-298. [CrossRef]

80. Hunt, C.A.; Durham, W.H.; Driscoll, L.; Honey, M. Can ecotourism deliver real economic, social, and environmental benefits? A study of the Osa Peninsula, Costa Rica. J. Sustain. Tour. 2015, 23, 339-357. [CrossRef]

81. Xue, L.; Kerstetter, D. Rural Tourism and Livelihood Change: An Emic Perspective. J. Hosp. Tour. Res. 2019, 43, 416-437. [CrossRef]

82. Klein, R.A. Dreams and Realities: A Critical Look at the Cruise Ship Industry. In Tourists and Tourism: A Reader; Gmelch, S.B., Kaul, A., Eds.; Waveland Press: Long Grove, IL, USA, 2018; pp. 247-258.

83. McKinley Research Group. The Economic Impacts of COVID-19 on Alaska's Visitor Industry; Anchorage, AK, USA, 2021. Available online: https:/ / www.alaskatia.org/wp-content/uploads / ATIA-COVID-Impacts-on-Visitor-Industry-6_3_21.pdf (accessed on 7 June 2021).

84. Leffler, J. Wrangell Doesn't Want Cruise Ships to Dock Until It Knows Port Communities Will Be Safe from COVID-19|KSTK. 2020. Available online: https:/ / www.ktoo.org/2020/05/29/wrangell-doesnt-want-cruise-ships-to-dock-until-it-knows-portcommunities-will-be-safe-from-covid-19/ (accessed on 7 June 2021).

85. Berg, B. Why 2021 Will Be the Year of the Alaska Micro-Cruise. Washington Post, 25 March 2021. 